\title{
Aquaponics: prospects and challenges in Nepal
}

\section{Bidika Subedi*, Manita Paudel}

Agriculture and Forestry University, Chitwan, Nepal

*Corresponding email: bidhikasubedi@gmail.com

\begin{abstract}
Aquaponics is the integration of recirculating aquaculture and hydroponics in one production system. Nepal as an agricultural country has a higher prospect of this system. As the demand for fish and healthy vegetables and fruits are increasing in Nepalese market, aquaponics can be flourished as an alternative way for the optimum utilization of resources. With the increasing population, urbanization and industrialization, the land has been scarce for agriculture which leads to the higher scope of aquaponics to enhance the food security. Aquaponics is the sustainable, eco-friendly and intensive farming system that enhances the domestic food production or pre-urban and urban food security. Besides all the benefits, there are various challenges that limit the adoption of aquaponics system in Nepal. The major challenge is the high initial cost and requirement of adequate technical knowledge to maintain the balance of this system. The others are the lack of government policies and priority, lack of proper marketing for perishable products, load shedding etc. Hence, the government should give priority to the aquaponics system for the enhancement of food production in Nepal.
\end{abstract}

Keywords-Aquaponics, hydroponics, agriculture.

\section{INTRODUCTION}

Sustainable production, food and nutritional security has become a serious issue in the global market with the increase in human population. With the increasing urbanization, industrialization and land fragmentation, there will be the scarce land resources for the agricultural production to support the global population. In the context of Nepal, most of the people practice the traditional way of agriculture farming due to which, it is unable to meet the demand of agricultural products. In this scenario, fisheries and aquaculture seems to be the future towards food security as it is a crucial source of animal protein. Nepal is a developing country where agriculture is the main source of food, income and employment for the majority of people.According to the world bank collection of development indicators, agriculture supports $65 \%$ of total employment in Nepal and contributes $24.26 \%$ to the gross domestic product in 2019 (Statista, 2020). Similarly, the fishery sector contributes $4.18 \%$ to agricultural gross domestic product (AGDP) and $1.13 \%$ to gross domestic product (GDP) in fiscal year 2018/19. The annual production of fish has increased from 86,544 metric tonnes in $2017 / 78$ to 91832 metric tonnes in $2018 / 19$ with an increment of $6.11 \%$ (MoALD, 2020). However, the present aquaculture systems are facing challenges like water-quality management, diseases and traditional way of practicing which gives scope for the advanced technology to address these major challenges and boost up the production in quality and quantity. Similarly, the effluent from the production system has resulted in water pollution which has been a matter of concern for all the people. Hence, aquaponics is a sustainable and eco-friendly system for the enhancement of aquaculture production.

Aquaponics is the combination of two farming practices; aquaculture and hydroponics (Love et al., 2014). Aquaponics is a modern food production system which combines aquaculture and hydroponics (Raising of plants without soil beds) together symbiotically in a balanced recirculatory environment (Azad et al., 2016). Recirculatory environment signifies the reuse of the same water again and again through the biological filter to limit the toxic waste materials. It is a symbiotic relation between fish and vegetables where fish provides fertilizers to the plants and in return plants help to purify the wastewater as they use the nutrients where the fish live in (Roe and Midmore, 2008). This integration makes it much more profitable as compared to the conventional methods. The system is considered environmentally sustainable with the production of diversified high value products throughout the year.

\section{History:}

Aquaponics has an ancient root as its primal practice can be traced back to around $1000 \mathrm{AD}$ where Aztec Indian raised plants on the rafts on the surface of a lake, known as Chinampas production system. Then, followed with the introduction of fish into paddy, rice fields in South-East 
Asia about 1500 years ago (Coche, 1967). The term 'Aquaponics' was coined in 1970s .In the late 70s and 80s, researchers at the new Alchemy Institute North Carolina State University (USA) developed the basis of modern aquaculture (Love et al., 2014). The first closed loop system and first large-scale commercial facility started in the mid 1980s. After that, it has gained the momentum and interest among the global community.

In the context of Nepal, it is still in its rudimentary stage. It is only practiced in few cities like Syangja, Surkhet and Kathmandu. "Hope Nepal Bioponics", an agri-business private company, has been pioneering aquaponic food production in Nepal since 2006 (Adhikari et al., 2020). The Rotary Club of Patan, Nepal and the Rotary Club of Brussels with funding from Rotary International and technical support from the social enterprise, aquaponics UK had already run an aquaponics unit that supports a rehabilitation home for 20 children and mothers affected by HIV/AIDS (Mallypaty, 2012). The experimental evaluation in outdoor barrel aquaponics performed in IAAS, Paklihawa is a significant step towards the promotion of aquaponics in Nepal (Gyawali et al., 2019).

\section{PRINCIPLE}

Aquaponics is a freshwater ecosystem with the interaction between its biotic and abiotic components. The biotic components constitute fish, plants and bacteria while abiotic component constitutes water, air, grow beds and fish tank. The fish tank is set up and the fishes are provided with supplemental feeds. The nutrient rich water of fish tank is used to fertilize the grow beds. The feed supplied to the fish doesn't account for the total biological conversion. The uneaten feed undergoes decomposition and the waste released by fish both make the water foul and undesirable for fish. The fish takes $20-30 \%$ of the $\mathrm{N}$ supplied by the feed (Schneider et al., 2005) and the rest is deposited in the culture media (Krom et al., 1995). This increases the toxic level in the tank affecting the fish growth. The nitrifying bacteria residing on grow beds convert the toxic ammonia and nitrite into less toxic form of nitrate. Nitrate is assimilated by the plants that enhances the nitrogen use efficiency (NUE), and thus creates a better environment for fish in the aquaculture tank when water is again re-circulated in the fish tank (Wongkiew et al., 2017).

\section{MECHANISM}

Aquaponics system relies on the natural sets of processes between the fish and bacterial community to produce the hydroponic plants. In this system, fish doesn't consume the overall supplied feed for its growth and metabolism. A small part (less than 5\% (Yogev et al., 2016) is left uneaten and hence decomposed.This decomposition of uneaten feed and the faecal matter produced by the fish increases the nutrient load of the water leading to the consumption of dissolved oxygen and increasing the release of carbon dioxide and ammonia (Losordo et al,. 1998). This released ammonia is toxic to fish species even in minimal quantity whose toxicity increases with the increasing $\mathrm{pH}$ and temperature. To balance the nutrient cycle in this closed loop, the bacterial community has a significant role. They feed upon the uneaten feed, decayed matter and nutrient loaded fish waste. The beneficial bacterial community performs the nitrification process for the stabilization of nutrient cycle.

Nitrification is a two- step process where in first step the fish waste in the form of ammonia(NH3) or ammonium (NH4+) is converted into nitrite(NO2-) by ammonia-oxidizing bacteria (AOB) like Nitromonas, Nitrosococcus, Nitrosospira. Likewise, in the second step of nitrification, toxic form of nitrite is converted into less toxic form of nitrate(NO3-) by nitrite-oxidizing bacteria (NOB) like Nitrobacter, Nitrococcus (Rurangwa and Verdegem 2013; Timmons and Ebeling 2013; Wongkiew et al. 2017). Nitrate is the form of nutrient which the plant can assimilate and are stripped by the plants from the water tank where the fish resides. When the nutrient system stabilizes, the water becomes clear and favorable for the growth of fish. In aquaponics, nitrate in excess is used for the valuable plant production instead of being removed in gaseous form in denitrification units (Van Rijn, 2013).In this process when there is a constant supply of water, the recirculation occurs in its own pace, supplying the required nutrients for the optimum growth of plants and creating sound habitat for the fish. Hence, it is a synergistic approach between fish, plants, bacteria and so on to create a sustainable and eco-friendly production system; which reduces the operational cost (Salam et al., 2013).

\section{Suitable fish species in aquaponics system:}

Fish is the component of aquaculture in an aquaponics system. It is the source of nutrient rich water for the hydroponic plants cultivated in grow beds. It can be reared in round, rectangular or elliptical tanks depending upon the design and cost of operation. Since, these tanks are the living space for the fish; various parameters like good water quality (adjustment of ammonia, nitrite and oxygen), adequate level of oxygen and the removal of waste should be maintained.

Selection of fish species should be done under various considerations. They should be able to live in dense 
population, thrive in less dissolved oxygen and should have a capacity to attain fast growth even in a confined environment. Several warm-water and coldwater fish species are adapted to recirculating aquaculture systems (Diver, 2006); including Tilapia (Oreochromis niloticus), Trout (Oncorhynchus mykiss), Perch (Perca), Arctic char (Salvelinus alpinus), Largemouth bass (Micropterus salmoides) (Diver,2006). Among these Tilapia is the fish species which has been selected in the study and practice. The experimental evaluation in outdoor barrel aquaponics was practiced in IAAS Paklihawa (Gyawali et al., 2019) with the stocking of Bighead carp (Aristichthys nobilis) and Common carp (Cyprinus carpio) which resulted in high survival rate and growth rate. The farmers of syangja district are growing Rohu, Naini, Silver and Common carp (Gurung, 2018).

\section{Suitable Plants Species in aquaponics system:}

Plants are the hydroponic component of the aquaponics system. They are cultured in the grow beds where the nutrient rich water is supplied through the fish tank. Since, aquaponics is a recirculating system, the waste water is regulated by the plants while stripping the excess nutrients in the form of nitrate. This results in their optimum growth. Therefore, the selection of plant species adapted to hydroponic culture in aquaponic greenhouses is related to the stocking density of fish tanks and subsequent nutrient concentration of aquaculture effluent (Diver, 2006). Both leafy vegetables and fruits can be harvested from aquaponics (Azad et al., 2016). Leafy vegetables like lettuce, spinach, chives, basil with low to medium nutritional requirements along with cabbage, carrots, okra (Salam et al,. 2013; Azad, 2015) are adoptive in the aquaponic system. Fruits like tomato, bell pepper and cucumber have a high nutritional requirement and perform better in a heavily stocked, well developed aquaponics system (Diver 2009). With further advancement in the system, it increases the potentiality for the production of flowers and medicinal plants. The experimental evaluation in outdoor barrel aquaponics was practiced in IAAS Paklihawa (Gyawali et al., 2019) with the cultivation of Broad leaf mustard of different varieties which showed the high yield. The farmers of Syangja district are growing garlic, cucumber, tomatoes, carrot, onion and coriander on stones while spinach, chilly, strawberry, potatoes and mint on PVC pipes and broccoli and Cauliflower in thermocol (Gurung, 2018).

\section{Prospects of Aquaponics in Nepal:}

As the income and livelihood of majority of Nepalese farmers depend on both the farming of vegetables and fruits, there is a high prospect of aquaponics in Nepal. In the context of Nepal, though it is practiced in some cities, it is still in its lagging phase, but a positive growth and expansion can be expected because of its various benefits and adoptive nature. Nepal is still under privileged in terms of proper dietary, food and nutritional security. Nepal is unlikely to achieve the daily standard requirement of 30 gram of fish or meat protein any time soon (Gurung, 2016). As a result of less intake of proper diet, many people are facing nutritional deficiency disease. Fish is an excellent source of omega-3 fatty acids, protein, vitamins, iron,zinc and fat soluble vitamin D. The fish production per capita in 2017/18 was $3.10 \mathrm{~kg}$ and fish availability per capita was $3.39 \mathrm{~kg}$ in Nepal (CFPCC, 2018). As seen there is a gap between the production and available amount of fish which is filled by the import from other countries. The fish was imported in a huge amount of 10,756 metric tonnes in 2017/18 (CFPCC, 2018). These imported fish lack the quality and are not beneficial in terms of health. To ensure the good health, proper diet, food and nutritional security Nepal needs to be self -sustained in terms of fish production. Similarly, vegetables are profound in Vitamins like $\mathrm{A}$ and $\mathrm{C}$, iron, zinc, potassium etc. In Nepal, there is an increasing demand of vegetables with the increase in the healthy and conscious eating habit. The production of both fish and vegetables can go hand on hand to improve the economic and nutritional status of the country.

Furthermore, the rapid urbanization, industrialization and various other purposes has taken over the agricultural land and created much more pressure on the available natural resources. The lack of arable land in urban areas has given a new approach of rooftop farming, home gardening etc. The major city where there is scarce land and water resources has been adopting this aquaponics technology. Since, it can be practiced in the backyard or rooftop, it ultimately reduces the cost of transportation and ensures the quality of products. It accounts for the better health of the consumers since it provides the required nutrients like protein, vitamins without any growth stimulants and toxic chemicals. The consumers are concerned more about the organic food though they have to pay a little more amount. It is said that, a simple aquaponics system grows 6 times more per square foot than traditional farming and accounts for $70 \%$ less energy than the conventional method. The aquaculture and agricultural land of Nepal depends on the ground source of water. With the passing time these sources are being dried up as a result of which the agricultural production of Nepal has been affected to a great extent. While on contrary, the aquaponics system operating in a recirculatory mechanism saves about $95 \%$ of water (Dalsgaard et al., 2013); using only $10 \%$ of it. In this 
scenario, this aquaponic technique is a boon for the urban community.

Aquaponics is much more convenient than traditional farming practice as it does not require ploughing, mulching, tilling operations. This saves much more time and cost. Similarly, the yield that is reduced in soil culture due to soil borne pests is discarded in aquaponics which increase the production. The harmful effect of pesticides in both fish and plants are not pronounced in this technology, favoring better public health.

To combat the growing demand of vegetables and fish with increasing market value, the local production incorporating aquaponics could be handy for the future generations. Thus, the chemical-free, fresh, nutritious vegetables and good quality fish can be produced through the aquaponic system and thereby sound health can be maintained (Azad, 2015). This technology can serve a key point to maintain the healthy and sustainable food production and security in Nepal.

\section{CHALLENGES}

Though aquaponics system tend to have enormous benefits, it is still in rudimentary stage and has not been widely accepted. It is a sophisticated technology; the farmers don't possess knowledge and awareness regarding the operation of this system. This has created a hindrance for the potential production of the system. Since, it covers multi -disciplinary areas, it requires vast knowledge regarding the management and monitoring of water quality parameters. The stabilization of $\mathrm{pH}$ and nutrient recycling are the major concern since the nitrification process directly changes the amount of $\mathrm{pH}$ affecting the nutrient assimilation by plants.

Along with technical challenges, it also faces the economic burden. The highly sophisticated technology requires a huge amount of money for the initial setup. Nepal, faces the problem of load shedding, this power cut in an enclosed system even for a short system disturbs the balance between the entities both abiotic and biotic resulting in a loss. To co-operate with this problem the farmers need to install inverters or generators in the farm, which causes a financial burden, increasing the cost of operation.

The nutrient loaded water when becomes turbid and unfavorable, may increase the susceptibility of fish towards diseases like fin rot and white spots. This problem can be managed by avoiding the overstocking of fish which signifies less fish during the harvest. However, there is a deficiency of available research to encourage the development of economically efficient aquaponic systems in Nepal. This has also limited the implementation of aquaponics commercially on a large-scale. Nepal is still under the line of poverty where the adoption of this highly sophisticated technology requiring vast theoretical and practical knowledge, highly skilled manpower with huge capital investment is still a big thing for the developing third world country like Nepal. These socio-economic and technical challenges have been a hurdle in the way of expansion of aquaponics.

\section{Recommendation:}

- The knowledge and experience sharing programmes should be launched to increase the awareness of farmers towards the aquaponics.

- The local farmers should be provided the training sessions regarding the installment and operation of aquaponics.

- The prerequisites like fish seed, feed etc should be evaluated by the government and provided to the farmers.

- The government should establish a proper market for the farmers to sell their harvest at a reasonable price.

- Government should provide funds and subsidies to the farmers in order to encourage their work.

- Governmental policies and research and extension works regarding this innovative system should be focused and given utmost priority.

- The local government should work in co-ordinance to form a congenial plan for the promotion and upliftment of aquaponics; to make the cities self -sustained on the production of fish and vegetables.

\section{CONCLUSION}

Nepal is an agricultural developing country where agriculture should be given as a functional priority by the government to succeed in the days ahead. Food security is the major problem faced by the modern world. To reduce this problem the modernization and commercial farming system should be introduced. One of the major food sectors to support food security in the present scenario is fisheries and aquaculture. The integrated system of the production of both plants and aquaculture species is best for the optimum utilization of input resources. In this regard, aquaponics is the one of the emerging modern technologies to ensure the production of plants like vegetables, fruits etc. and aquaculture species like fish in the same area under symbiotic relationship.

As aquaculture is increasing rapidly in Nepal with the increasing rate of $6.11 \%$ in fiscal year $2018 / 19$, there are 
high prospects of practicing aquaponics system. The involvement of farmers in fish farming is increasing in Nepal and also many youths are attracted to the modern technology system of farming. Aquaponics can be the opportunity for the Nepalese youths to generate income and employment. Besides these prospects and various benefits of the aquaponics system, there are many challenges faced by farmers as it is a sophisticated system. Lack of adequate technical knowledge leads to failure of this system and also the initial cost of this system is high due to which farmers are afraid of rapid adoption of this system. Lack of proper research and government policies, lack of technical knowledge, economic constraints due to poverty of farmers, load shedding as it requires continuous electricity supply are the major challenges in the context of Nepal. Hence, for the further expansion of aquaponics in Nepal the government should make the policies and give priority to the research, extension and training related to the aquaponics system.

\section{REFERENCES}

[1] Adhikari, R, Rauniyar, S, Pokhrel, N, Wagle, A, Komai, T and Paudel, S.R., 2020. Nitrogen recovery via aquaponics in Nepal: Current prospects and challenges. A case study published on SN Applied Sciences, 2020, article number:1192.

[2] Azad K.N., 2015. Comparative study of okra production using different bedding media in aquaponic system. MSC thesis, Department of Aquaculture, Bangladesh Agricultural University.

[3] Azad, KN, Salam M. A, Azad, K.N. (2016) Aquaponics in Bangladesh: current status and future prospects. Journal of Bioscience and Agriculture Research,2016. Vol. 07, Issue 02:669-677.

[4] Statistical information on Nepalese Agriculture, 2020.Ministry of Agriculture and Livestock Department; Planning and development cooperation coordination division, statistics and analysis section: Singhadurbar, Kathmandu, Nepal. www.MoALD.gov.np

[5] CFPCC, 2018. Annual book. Balaju, Kathmandu: Government of Nepal; Ministry of Agriculture and livestock Department, Department of livestocks. Central Fisheries Promotion and Conservation Centre.

[6] Coche, A.G.,1967. Fish culture in rice fields: a worldwide synthesis. Hydrobiologia 1967, 30(1): pp 1-44

[7] Dalsgard J., Lund I., Thorarinsdotti R., rDrengstig A., Arvonen K. and Pederson P.B., 2013. Farming of different species in RAS in Nordic countries: current status and future perspectives. Aquaculture Engineering; 53,2-13.

[8] Diver S (2009) Aquaponics-Integration of Hydroponics with Aquaculture. ATTRA.

[9] Gurung Mohan, 2018. Syangja farmer using aquaponics to vegetables. https://myrepublica.nagariknetwork.com/news/syangja-farm er-using-aquaponics-to-grow-vegetables/

[10] Gurung TB, 2016. Role of inland fishery and aquaculture for food and nutrition security in Nepal. Agriculture food security 5 (1): 18.

[11] Gyawali, S, Chaudhary, P, Chaudhary, M, Gurung, S and Pathak R (2019) Comparative evaluation of Broad Leaf Mustard (BLM) under different boron concentrations in outdoor barrel aquaponics at IAAS, Paklihawa. International Journal of Applied Science and Biotechnology 7(3):359-364

[12] Krom MD, Ellner S, Rijin JV and Neori A (1995). Nitrogen and phosphorus cycling and transformations in a prototype 'non-polluting' integrated mariculture system, Eilat, Israel. Marine ecology progress series 118: 25-36.

[13] Losordo TN, Massen MP, Rakocy J, 1998. Recirculating aquaculture tank production systems: an overview of critical considerations. SRAC No. 451, pp 18-31.

[14] Love et al., 2014. International survey of aquaponics practitioners. Plos one, 9(7), e102662.

[15] Mallapaty S., 2012. Nepal sees potential in aquaponics. https://www.scidev.net/global/biotechnology/news/nepal-see s-potential-in-aquaponics.html

[16] Nepal: distribution of Gross Domestic Product (GDP) across economic sectors from 2009-2019. Statista, 2020.https://www.statista.com/statistics/425750/nepal-gdp-d istribution-across-economic-sectors/

[17] Roe and Midrmore, 2008. Sustainable aquaponics. Centre for plant and water science. CQ university, Pockhampton, Queensland, Australia (Issue 103; hydroponics and greenhouse)

[18] Rurangwa and Verdegem MCJ, 2013. Micro-organisms in recirculating aquaculture systems and their management, review. Aquaculture 7: 117-130.

[19] Salam, M.A., M. Asadujjaman and M.S. Rahman(2013). Aquaponics for Improving High Density Fish Pond Water Quality Through Raft and Rack Vegetable Production.World Journal of Fish and Marine Sciences, Volume 5 (3): 251-256

[20] Schneider O, Sereti V, Eding EH and Verreth JAJ, 2005. Analysis of nutrient flows in integrated intensive aquaculture system. Aquaculture Engineering 32: 379-401.

[21] Timmon MB, Ebeling JM, 2013. Recirculating aquaculture, Ithaca publishing, Newyork.

[22] Wongkiew S, Huz, Chandran K, Lee JW, Khanal SK, 2017. Nitrogen transformations in aquaponic systems: a review. Aquaculture engineering 76: 9-19.

[23] Yogev U, Barnes , Gross A, 2016. Nutrients and energy balance analysis for a conceptual model of a three loops off grid, aquaponics water 8 . 